\title{
FERTILITY STUDIES IN THE FIELD BEAN \\ (VICIA FABA L.)
}

\author{
I. CROSS- AND SELF-FERTILITY \\ D. G. ROWLANDS \\ Welsh Plant Breeding Station, Aberystwyth*
}

\section{INTRODUCTION}

Received I I.iii.6o

THE problem of self-fertilisation in flowering plants has an important bearing on practical breeding, as the conditions under which crops are cultivated may bear no relationship to those under which the species has originally developed. Stebbins (1950) considers that crossfertilisation which promotes greater flexibility, is the ancestral system, and that self-fertilised types have evolved repeatedly in response to selection pressure in favour of immediate fitness. The cultivation of pure populations of a single species results in selection pressure for fitness and it is not surprising that many of the oldest crop plants such as wheat and barley are inbreeding in character. In this context it is of interest to observe the breeding system of the field bean, a grain crop of comparable antiquity, and one in which considerable cross-fertilisation occurs in the field.

The Papilionacee, with some important exceptions, are noted for their extreme self-incompatibility, while the field bean appears to occupy an intermediate position between the two extremes. It has been customary to think of the restriction of self-fertilisation in terms of a personate Nicotiana type, with its characteristic all or nothing effect, but the restriction of self-fertilisation does occur in many other species and genera though to a less marked degree. For example, most of the grass species investigated set seed only imperfectly on selfing and the data available from other groups are broadly similar (Beddows, 193 I; Smith, 1944).

\section{SEED-SETTING ON SELFING}

Previous studies (Rowlands, 1958) have indicated that in beans the typical Papilionaceous flower has associated with it the necessity for tripping and better growth of foreign pollen, but pollen is already shed within the keel before the flower opens although unable to germinate until tripping has taken place. At the precise moment of tripping, foreign pollen would be introduced by the manipulating insect, with the greater chance of cross-pollination taking place. If this were the only mechanism restricting self-pollination, one would

* Now at Food Research Department, Unilever Limited, Colworth House, Bedford. 
expect that artificial tripping of the flowers would ensure considerable improvements in yields of seed but this is not so (fig. I).

The first point of interest is that approximately 5 per cent. of the population was completely sterile on selfing; secondly, the potential ovule number per plant varied from 300 to 700 so that nothing like the potential seed set was obtained even on the plant with the highest ovule number. The mean is around 20, or roughly 4 per cent. of the potential. Occasional plants from the same population, when grown in the field, frequently gave $300-400$ mature seeds, or 6o-70 per cent. of the potential, so that high seed fertility can occur under some conditions. Self-fertility is undoubtedly low, but fig. I does not indicate whether this is due to a smaller proportion of ovules being set. In fig. 2 may be seen the proportion of flowers set under various conditions of outcrossing and selfing.

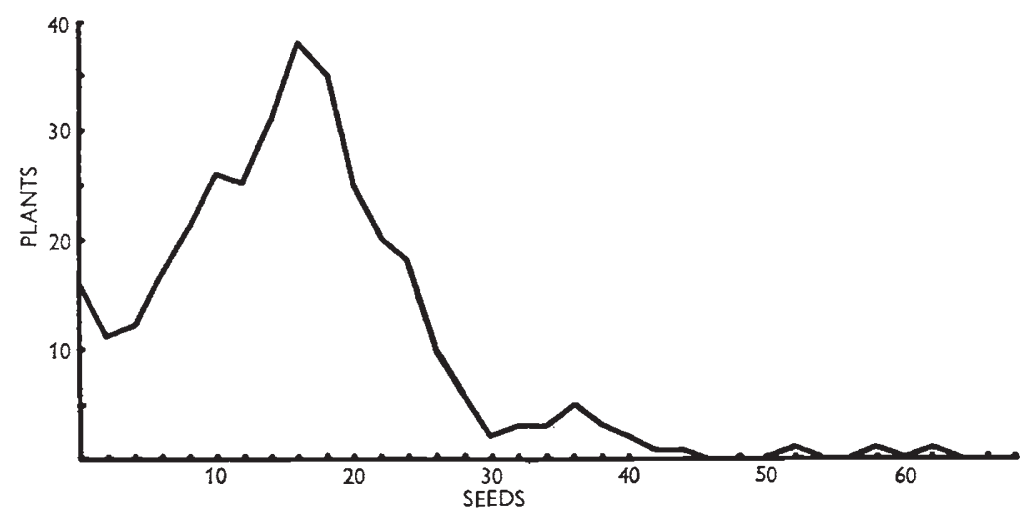

FIG. I.-Seed produced per plant after tripping.

Even under open-pollination in the field, the maximum seed set was $5^{\circ}$ per cent. with a mean of 24 per cent. If 70 per cent. of the seed is normally set by selfing in the field, then the approximate percentage of self-fertility under field conditions will be $16-18$, while selfing of the same population in the glasshouse after tripping gave a mean of 7.3 per cent. It would appear that the best plants in the open may have been cross-pollinated to a greater degree and the actual self-fertility thereby reduced to below 16 -1 8 per cent., the difference between the two years being due to glasshouse effect. Selfing of the 1956 progeny without tripping shows a high proportion of sterile plants, which could well be because of an inability to set seed without tripping, while the improvement in $195^{8}$ could be due to the selection of types capable of setting some seed without tripping. It is interesting to note the identical range of seed set in the 3 years. The effect of inbreeding on self-fertility will be described in detail in a subsequent paper. It then follows that some mechanism must be reducing the efficiency of self-pollination, and if this occurs before 
fertilisation then any inability of otherwise functional pollen to achieve fertilisation must be included in the category of self-incompatibility.

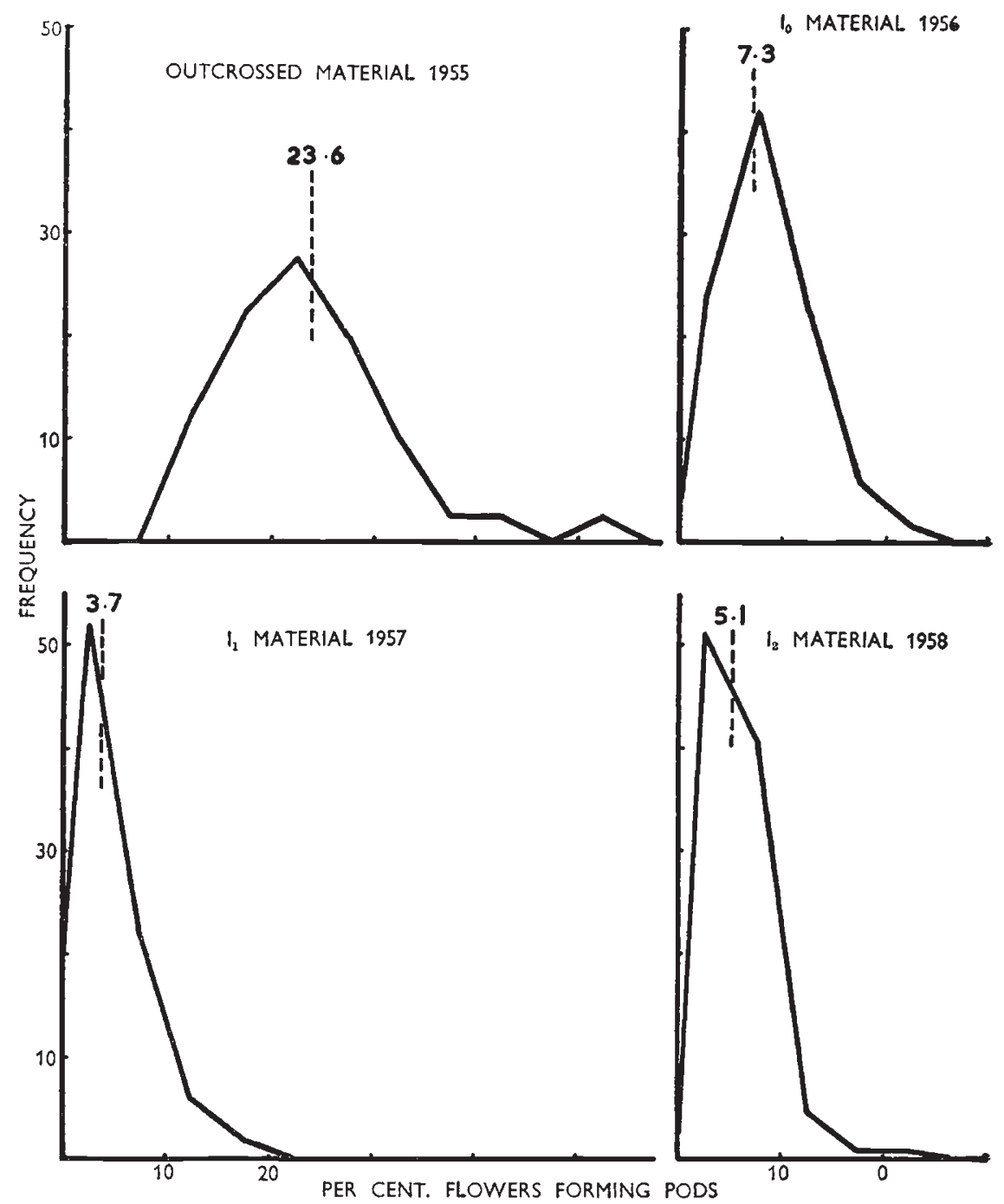

FIG. 2.-Frequency distribution of flowers forming pods in outcrossed and selfed material (per cent.).

\section{CROSS-FERTILITY}

In order to separate the factors involved a diallel cross was undertaken on six parent plants, selected as three pairs, each pair being obtained by selfing from a common parent. Previous selfing and crossing had indicated that position of the flower on the stem had an appreciable influence on pod setting, the lower flowers being more fertile. An attempt therefore was made to allow for this during the lay-out of the crosses. 
The six parents were crossed in all possible combinations, including the six selfings, and five flowers were used for each cross. Thirty flowers were required for each parent, but because there was only a limited number of flowers available it was inevitable that some unsuitable flowers had to be included with, of course, a corresponding increase in experimental error. The total number of seeds produced

TABLE I

Fertility diallel cross

Plants $=6,5$ flowers pollinated per cross :

fertility values $=$ seed per 5 flowers crossed

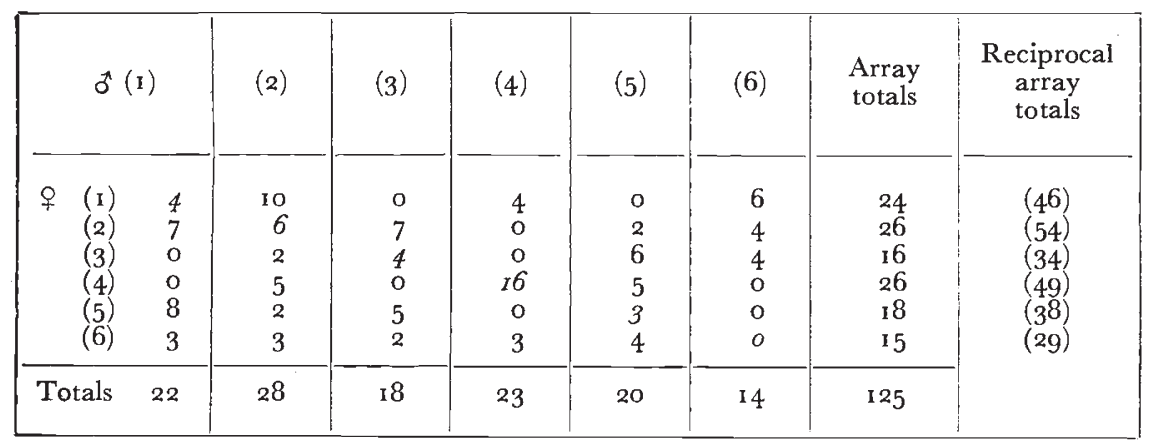

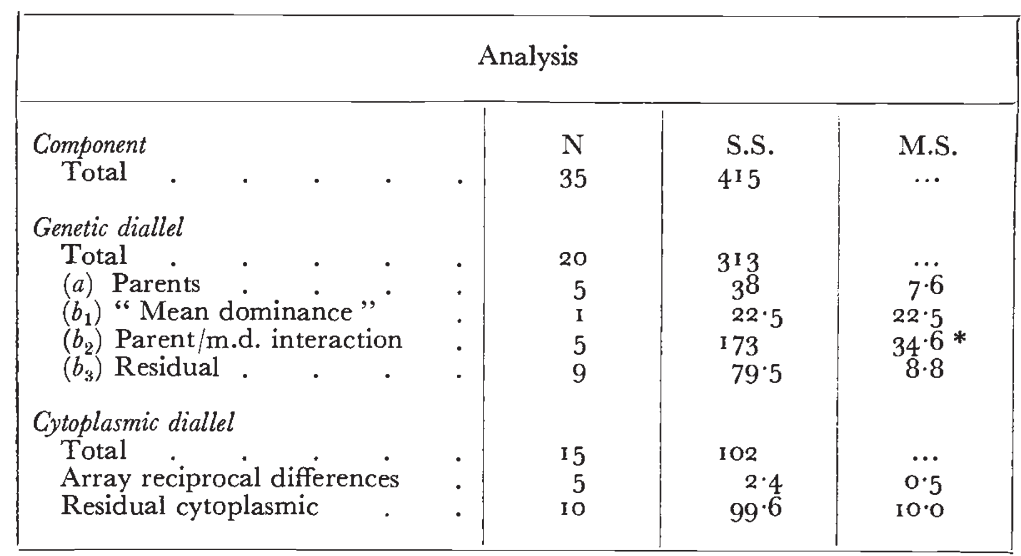

* Sig. at 5 per cent. level.

by each set of five flowers, together with the analysis of the results, are given in table $\mathrm{I}$.

The diallel cross analysis developed by Jinks and Hayman (1953) can be applied to the data, but the terms used are not directly comparable. From the above results and accompanying analysis in table I the following observations may be made:

(i) The differences between parents did not reach the level of significance, although parents 5 and 6 were the least effective in setting seed, particularly on selfing. 
(ii) The " residual cytoplasmic" component contains much of the experimental error, including reciprocal differences between individual values. Reciprocal differences between arrays were very small.

(iii) The "mean dominance" component applies to any overall superiority of crossing over selfing and is not significant, the reason for this may be the mechanical damage resulting from the crossing procedure.

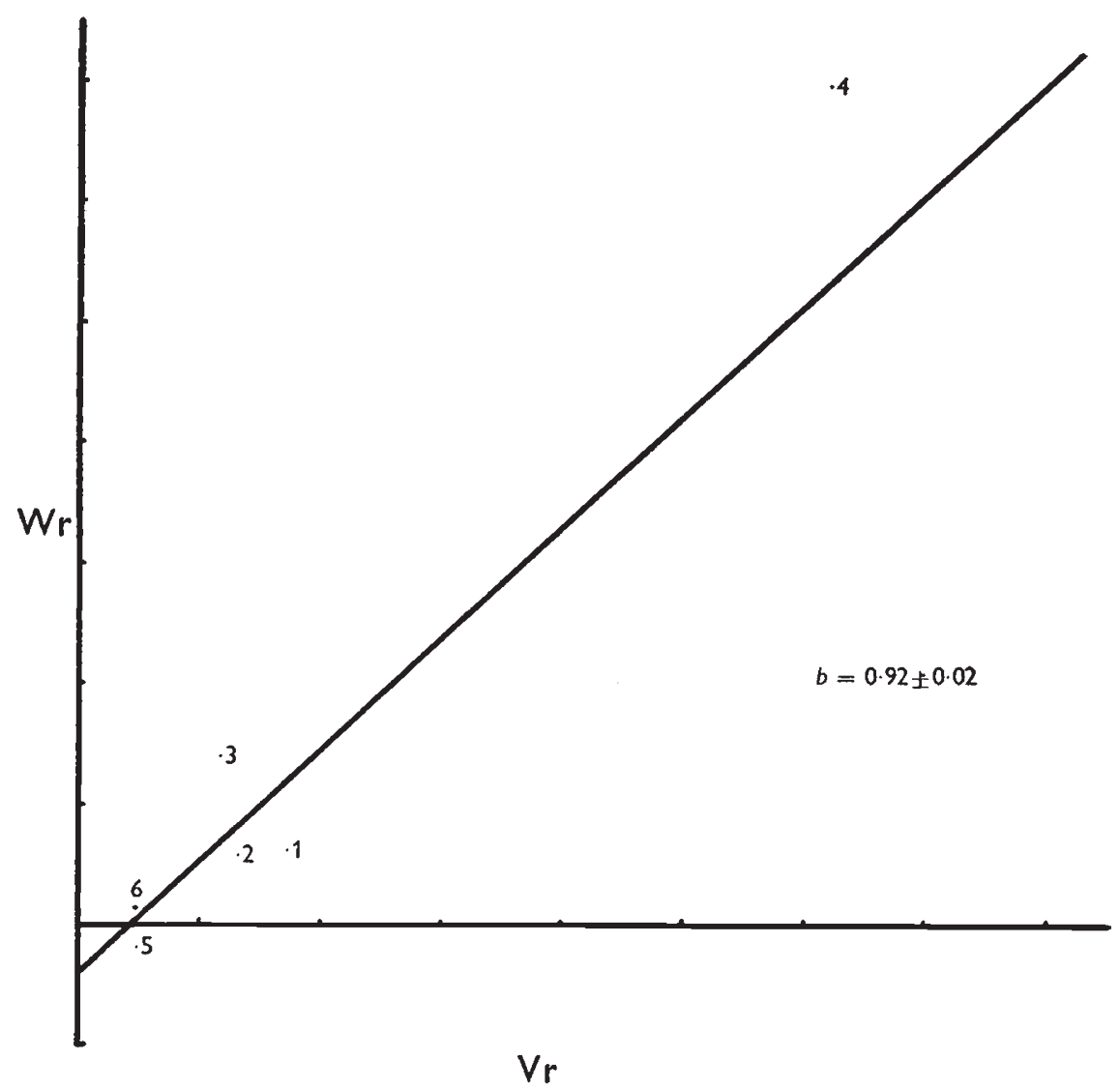

Frg. 3. $-\mathrm{Wr} / \mathrm{Vr}$ graph for seed set in main diallel. Complete data.

(iv) The $b_{2}$ component, or interaction, is significant at the 5 per cent. level over both errors and indicates that some parents cross better than others, I, 2 and 5 being better than 3,4 and 6 .

The $\mathrm{Wr} / \mathrm{Vr}$ graph for this diallel shows a significant regression line passing through the origin with a slope of $\mathrm{I}$, which indicates complete dominance and suggests a straightforward genetic system controlling general fertility. Parents $1,2,3,5$ and 6 contain the most dominant genes, and parent 4 the least. The data are barely significant but they suggest that fecundity or general fertility is recessive. 


\section{SELF-FERTILITY OF THE DIALLEL CROSS PROGENY}

The progeny from this diallel cross was subsequently grown in an insect-proof glasshouse and allowed to set seed without tripping. The small number of plants available did not allow for replication or

TABLE 2

Selfing of diallel progeny

(Reciprocal totals of mean seeds per plant)

\begin{tabular}{|cc|c|c|c|c|c|c|}
\hline & & & & & & & \\
Array \\
mean
\end{tabular}

Parent mean $=9 \cdot 9$.

* Estimated missing values.

an assessment of the effect of tripping and the values used for analysis were the means of the $2,3,4$ or 5 plants as available. The gaps in the analysis left by the sterile crosses in the previous generation were overcome to some extent by bulking reciprocals and doubling the

TABLE 3

Comparison between diallels

\begin{tabular}{|c|c|c|c|c|}
\hline \multirow{2}{*}{ Array } & \multicolumn{2}{|c|}{$\begin{array}{c}\text { Parents } \\
\text { Mean seed set on }\end{array}$} & \multicolumn{2}{|c|}{$\begin{array}{c}\text { Progeny } \\
\text { Mean self-fertility of }\end{array}$} \\
\hline & Crossing & Selfing & Crosses & Selfs \\
\hline $\begin{array}{l}\text { I } \\
2 \\
3 \\
4 \\
5 \\
6\end{array}$ & $\begin{array}{l}3 \cdot 8 \\
4 \cdot 2 \\
2 \cdot 6 \\
1 \cdot 7 \\
3 \cdot 2 \\
2 \cdot 9\end{array}$ & $\begin{array}{r}4 \\
6 \\
4 \\
16 \\
3 \\
0\end{array}$ & $\begin{array}{l}28 \cdot 4 \\
25 \cdot 9 \\
37 \cdot 0 \\
26 \cdot 9 \\
14.5 \\
29 \cdot 8\end{array}$ & $\begin{array}{r}25 \cdot 0 \\
10 \cdot 0 \\
16 \cdot 0 \\
7 \cdot 0 \\
0 \cdot 3 \\
1 \cdot 0\end{array}$ \\
\hline Mean & $3 \cdot 1$ & 5.5 & $27 \cdot 0$ & $9 \cdot 9$ \\
\hline
\end{tabular}

self and single values. Two gaps, however, still remained in the progeny of parent 3 and these were estimated from the array totals using the missing plot technique (table 2).

The self-fertility of the inbred parents in general is lower than that of their crosses, although I, 2 and 3 are more self-fertile than 4 , 5 and 6 (table 3 ). Parents 5 and 6 stand out with regard to selfsterility and also the self-sterility of their hybrids, and 3 has the most 
self-fertile crosses although the data here are less reliable. When the variances and covariances are plotted in the form of a $\mathrm{Wr} / \mathrm{Vr}$ graph the four following features are observed (fig. 4):

(i) Array 3 lies well away from the line and perhaps the estimates of the missing values may have something to do with this.

(ii) Parent 6 appears to be the most recessive and is also one of the least self-fertile. This indicates that self-sterility on the average is recessive.

(iii) The regression has a slope of $0.32 \pm 0.13$ which is not quite significant but very different from a slope of unity.

(iv) If this departure from unity slope is due to interaction, removal of one or more parental arrays should bring the line towards a slope

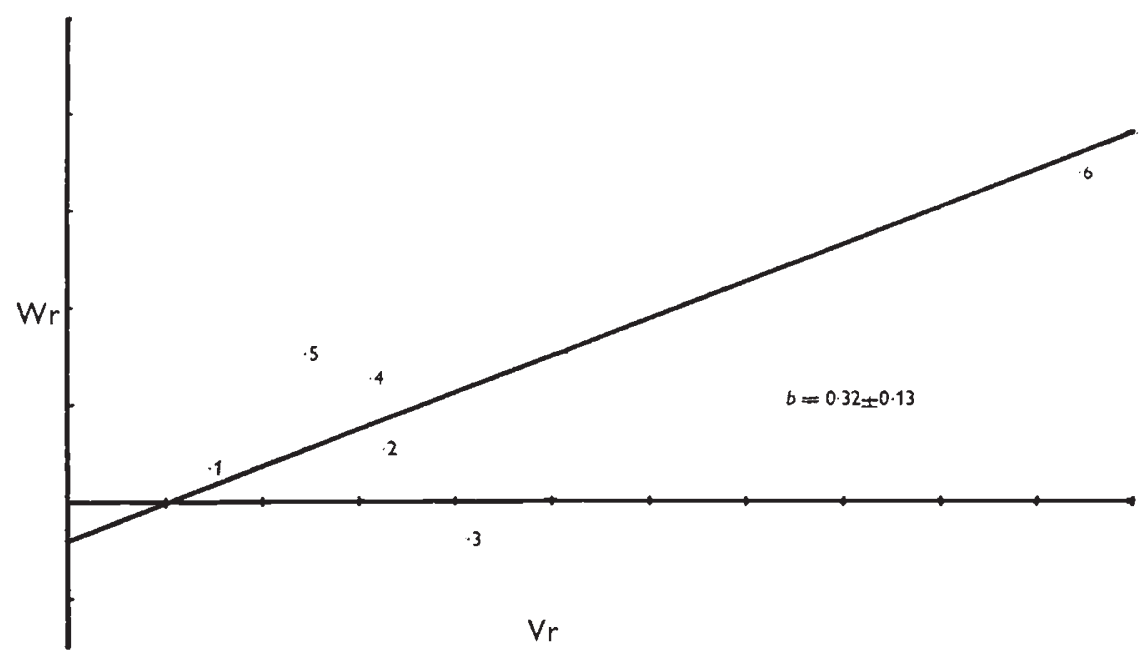

FIG. 4.-Wr/Vr graph for self-fertility of diallel progeny. Complete data.

of one. The most likely is array 6 , but on removal the line is not significant although the coefficient is nearer unity (fig. 5).

Removal of array 3 does not appreciably alter the slope $(b=$ $0.45 \pm 0.12)$ but the regression line now becomes significant at the 5 per cent. level. Estimates of missing values had to be made for two of the array 3 crosses and this effect may be due to some bias in their estimation. Scaling is generally unsuccessful in removing interaction although an improvement in slope has been attained by Whitehouse, Thompson and Do Valle Ribeiro (1958), in a wheat diallel using this method.

When the complete data are transformed to a simple log scale, the regression line in the $\mathrm{Wr} / \mathrm{Vr}$ graph is highly significant, and the slope has been improved, although it still differs from unity (fig. 6). Arrays 5 and 6 now stand out together while the remaining arrays lie nearer the origin. Omission of arrays 5 and 6 gives a further improvement of the slope and although only four points remain, the line is highly significant but still different from unity in slope. 


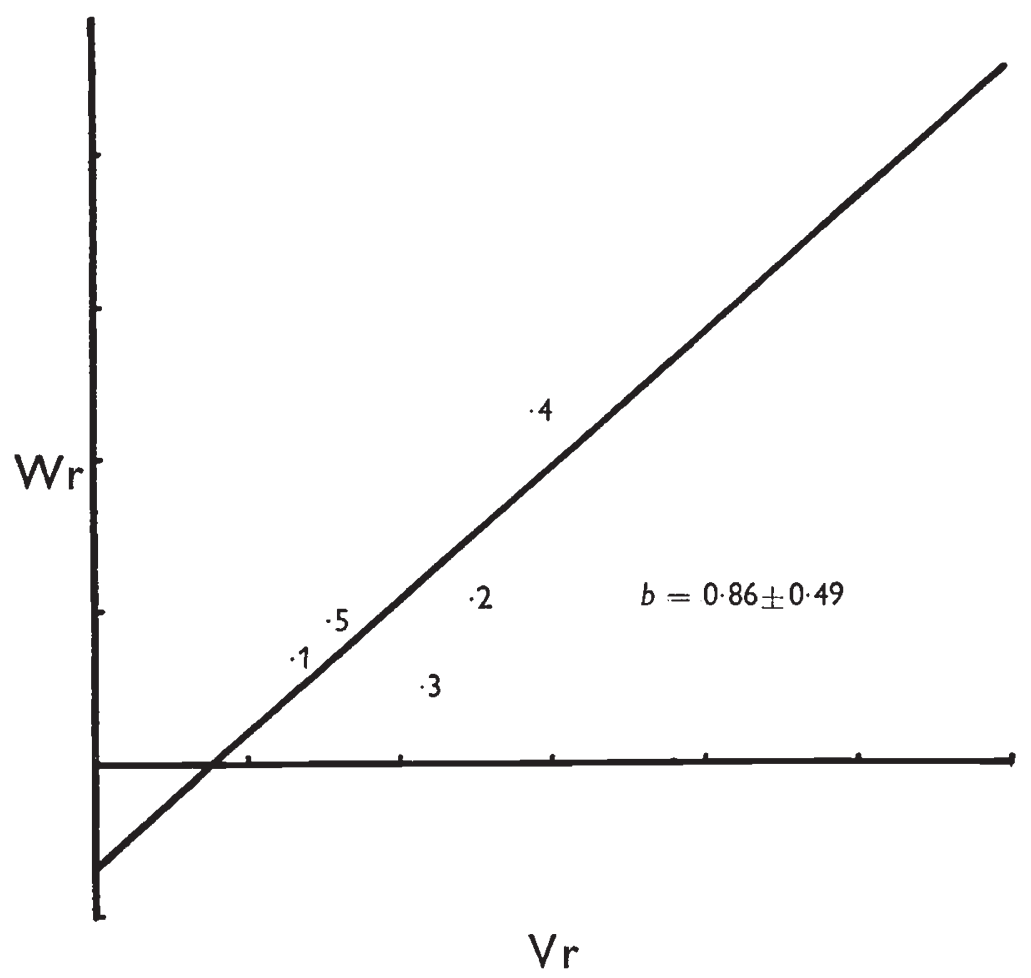

Fig. 5.-Wr/Vr graph for self-fertility of diallel progeny. Array 6 omitted.

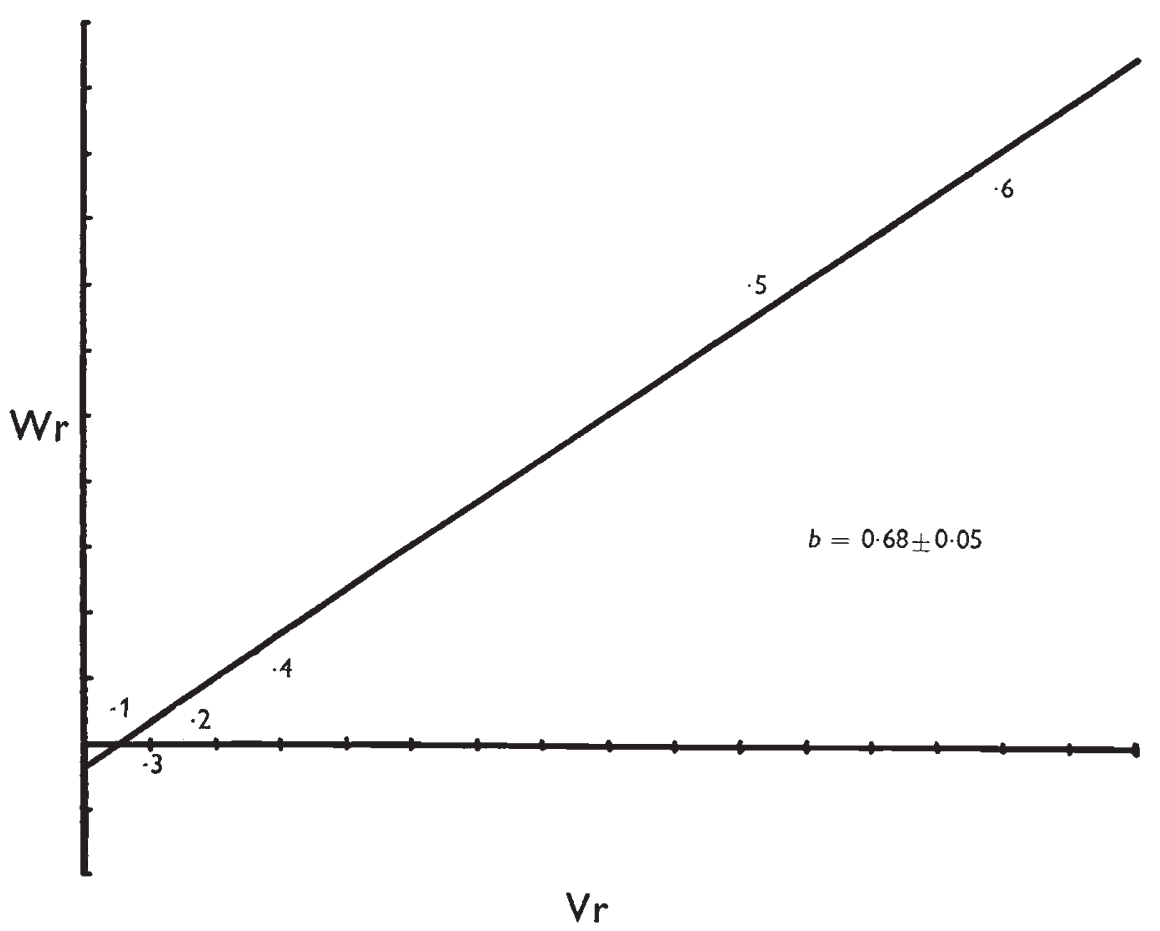

FIG. 6.- Wr/Vr graph for self-fertility of diallel progeny. Transformed data. 
In most of these groups, arrays I, 23 and 4 are nearer the origin than 5 and 6 and can thus be regarded as possessing more dominant genes. Since these arrays are also relatively more fertile it may be inferred that the dominant genes confer self-fertility and the recessives sterility.

\section{DISCUSSION}

Three factors appear to be involved in seed setting in the field bean, (a) the basic fertility of the plant, that is, the number of fertile ovules produced, $(b)$ the mechanism of tripping which prevents selfpollen from having an opportunity to germinate before foreign pollen is introduced, together with the better growth of foreign pollen which is a secondary facet of this tripping mechanism, and $(c)$ the restriction of self-fertilisation.

The basic fertility of the plant is related to the number of flowers produced in that the number of ovules per ovary is fairly constant within a range of five to six. Flower number ranges from $5^{\circ}$ to ${ }^{\circ} 5^{\circ}$, although occasional plants have been recorded with as many as 200 to 300 . The maximum number of ovules produced is around $75^{\circ}$ and the minimum 250. The present data on selfing show a maximum seed set between 30 and 40 ovules per plant, which approximates to 20 per cent. of the minimum potential number. Even after artificial tripping had been performed the highest set was 60 ovules, or 25 per cent. Tripping does not appear to have increased the maximum seed setting on selfing but the mean has been improved through less plants failing to set seed at all. Tripping thus appears to be a secondary mechanism imposed upon a further system but acting independently of it.

Although all the effects observed in the diallel cannot be directly attributed to self-incompatibility, some genetic control of self-fertility is indicated by the data. The problem now arises of suggesting a suitable hypothesis to account for the facts.

Consider a simple gene hypothesis where

$$
\begin{aligned}
& A \text { is dominant to } a \\
& B \text { is dominant to } b \\
& \text { and } \\
& \left.\begin{array}{r}
A a b b \\
a B B b
\end{array}\right\} \text { are sterile combinations }
\end{aligned}
$$

that is, homozygosity of either recessive gene results in sterility of the fertilised ovule. Then the proportion of fertile ovules on selfing the double heterozygote is :

$$
\begin{array}{ccccc} 
& A B & A b & a B & a b \\
A B & + & + & + & + \\
A b & + & - & + & - \\
a B & + & + & - & - \\
a b & + & - & - & -
\end{array}
$$

i.e. $\frac{9}{16}$ or $5^{6}$ per cent., and in the simple heterozygote is $\frac{3}{4}$ or 75 per cent. 
If the number of segregating genes is increased the proportion of fertile ovules on selfing will follow the curve, until with 15 segregating genes only 2 per cent. will be fertile. This curve is a typical log-curve and transforming the proportions of ovules to the log scale we get a simple relationship between number of genes and proportion of fertile ovules. It is significant here that transformation of the diallel

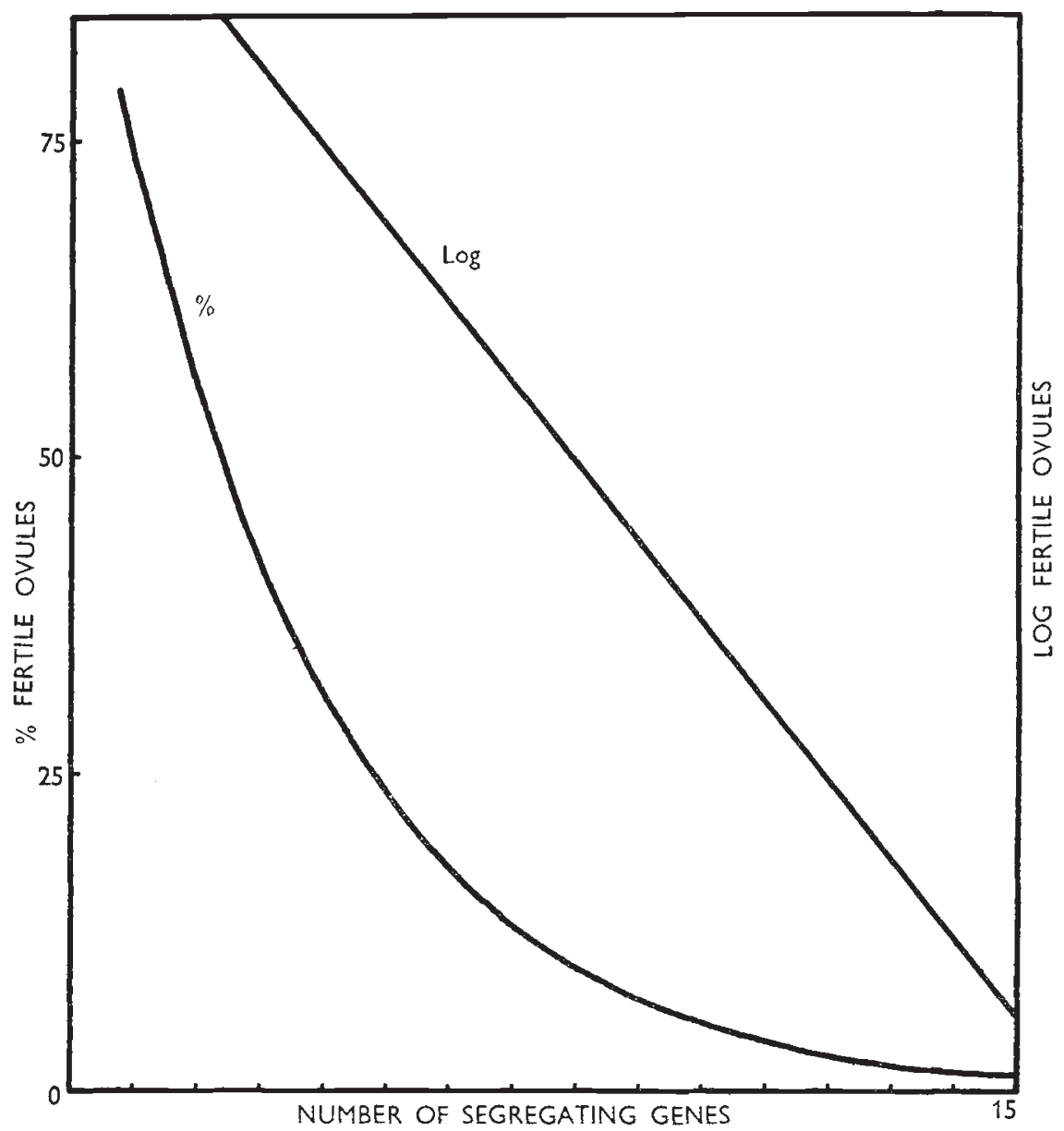

FIG. 7.-Relationship between the proportion of fertile ovules and the number of segregating genes.

data to the log scale increased the slope of the $\mathrm{Wr} / \mathrm{Vr}$ regression towards unity, and therefore there is a similar simplification of the genetic relationship between the parents.

It is also interesting to note that on crossing two plants with different numbers of segregating genes the fertility would be related to that of the more fertile plant, and crossing would give the impression of greater success, although it might only equal that of the more fertile parent. The preceding argument now allows us to comment on the possible mode of development of this type of self-sterility. 
One can envisage the progress of the early Papilionacee towards increased outbreeding by the development of an entomophilous flower shape. This by itself could only allow slight improvement in the chance of foreign pollen effecting fertilisation, but the development of a tripping mechanism to prevent self-pollen germinating until foreign pollen is present would increase the chances of crossfertilisation to 50 per cent. Any further improvement in cross-fertilisation would best be obtained by direct inhibition of pollen of matching genotype. Such a system is characteristic of many of the modern Papilionacee. Inevitably associated with such a system is the accumulation of deleterious recessive genes which on the breakdown of the pollen inhibitory reaction would be capable of causing considerable self-sterility. It is quite conceivable that in the field bean intense selection pressure towards selfing has caused such a breakdown of the pollen-inhibiting reaction, if not completely then at least towards a complementary reaction favouring foreign pollen. The subsequent zygotic infertility resulting from the deleterious recessives could be regarded as the resistance of the system to change. Where insect pollination is unsatisfactory, additional pressure towards selfing is applied to the system. The present situation is therefore one of balance, where the pressure to inbreed brought to bear by the conditions of cultivation and unsatisfactory insect pollination is counteracted by the requirement for tripping and the zygotic infertility.

This zygotic infertility which would have arisen from the original incompatibility system, and now maintains some discrimination over the possible gene combinations, has in effect taken over the function of the original incompatibility system in reducing the efficiency of self-pollination. If incompatibility is regarded as the failure of certain genetic combinations then such zygotic infertility could be included under this heading. If, however, incompatibility is limited to the restriction of fertilisation then since it is a post-fertilisation process, zygote infertility cannot be termed incompatibility. Investigation of other genera and families, including the grasses, would probably show the above situation to be quite general whenever a successful selfincompatibility system has been modified either under pressure of cultivation or other environmental conditions, thus allowing the accumulated deleterious recessives to control self-fertilisation.

If the difference between the self-fertility of parent 4 in diallel analyses I and 2 was influenced by tripping, then it follows that to achieve high self-fertility without tripping in hybrids the genes controlling the ability to set without tripping must be dominant. If both the ability to set without tripping and also the self-fertility genes are dominant then an attempt must be made to continue for subsequent inbreeding only the homozygous-dominant types, which are only detectable on their breeding behaviour in the following generation. Simple selection for seed set on selfing would be successful in concentrating the dominant genes in a population. Such a system 
of selection is being followed up in field beans and will be discussed in a later paper.

Additional evidence in support of infertility at the zygotic level has been forthcoming from the inbreeding experiment. Large numbers of abortive pods have been observed; they have remained attached to the plant despite the fact that the ovules have not developed (plate). Normally, flowers drop off when pollination is unsuccessful, so it is concluded that fertilisation has occurred and that ovule abortion followed zygote formation. Histological studies are necessary, however, before the precise sequence of events can be established.

It is doubtful whether the proposed hypothesis is completely adequate but it can form a basis for further investigation of the system.

\section{SUMMARY}

I. A maximum flower set of 50 per cent. was recorded in openpollinated material, with a mean of 24 per cent. Selfing the same population in a glasshouse gave only $7 \cdot 3$ per cent. even after tripping the flowers.

2. A diallel cross involving six parent plants was not effective in demonstrating any overall superiority of crossing over selfing, but showed that some parents crossed better than others.

3. Spontaneous self-fertility of the progeny from the diallel cross showed large differences between parents, numbers 5 and 6 being highly self-sterile.

The $\mathrm{Wr} / \mathrm{Vr}$ graphs indicate an interaction, an effect which could be largely removed by scaling. Omission of arrays 5 and 6 gives a further improvement of the slope although the slope still differs from unity. It is inferred from the relative position of the arrays on the graph that the dominant genes confer self-fertility and the recessive genes self-sterility. The data were also consistent with the necessity for tripping being dominant to the ability to set seed without tripping.

4. A hypothesis is put forward to explain this self-sterility in terms of homozygosity of deleterious recessive genes which can accumulate in any outbreeding system.

Breakdown of the original outbreeding system resulting from migration of the species from its centre of origin, and also by cultivation practices, would be followed by zygotic sterility caused by the deleterious recessive genes.

5. The implication of such a hypothesis on the possible development of inbred lines is discussed.

Acknowledgments.-I wish to thank Professor P. T. Thomas, Director of the Welsh Plant Breeding Station, for his advice and helpful criticism throughout the investigation. I am also indebted to Dr D. J. Griffiths for his help and encouragement, and to other colleagues at the Welsh Plant Breeding Station for helpful criticism. 

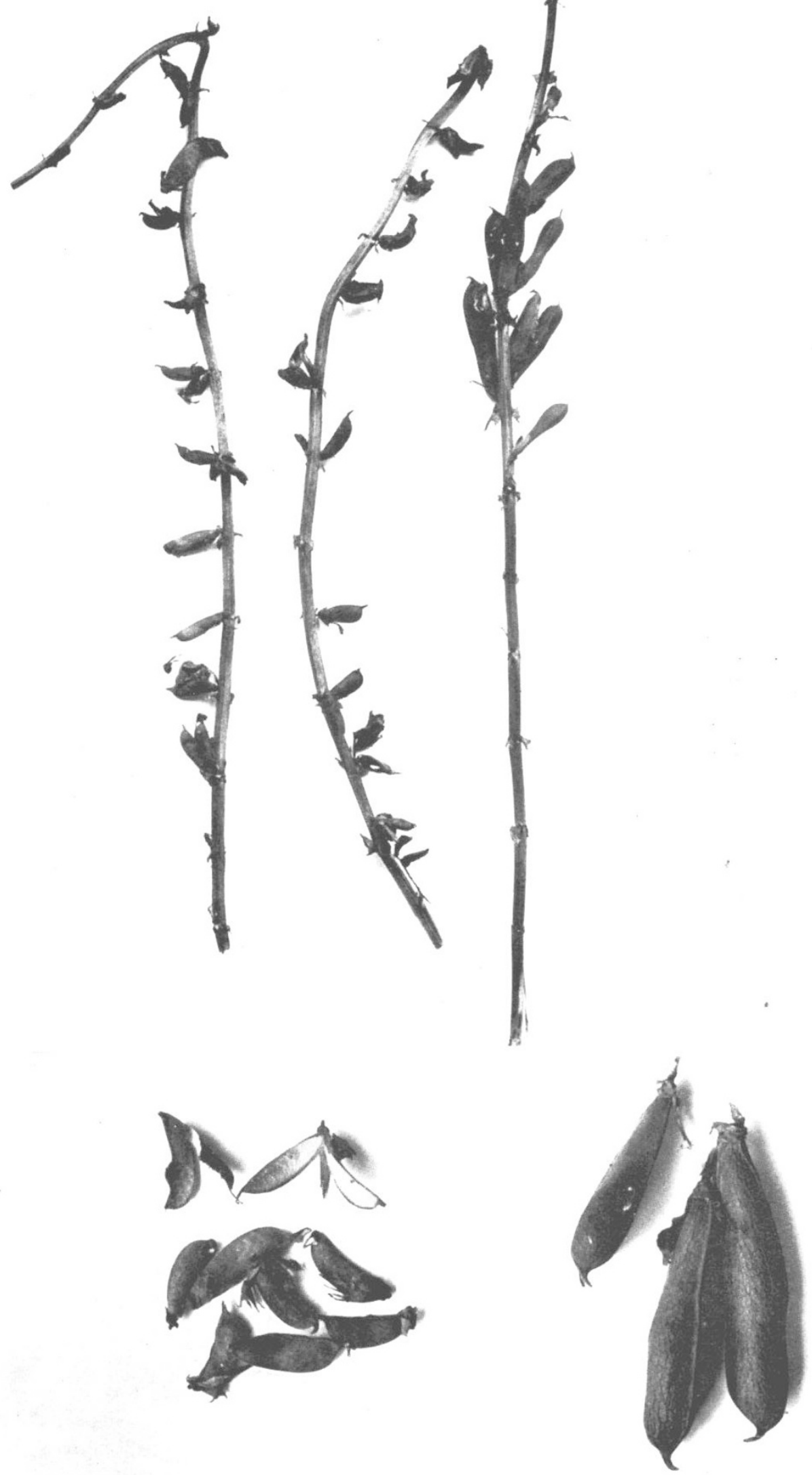

(a) Aborted pods.

(b) Fertile pods. Pod setting in selfed field beans. 


\section{REFERENCES}

BEDDOWs, A. R. 1931. Seed setting and flowering in various grasses. Bull. Welsh Pl. Breed. Sta. Series H, I2, 5-99.

JiNks, J. L. I955. A survey of the genetical basis of heterosis in a variety of diallel crosses. Heredity, 9, 223-238.

Jinks, J. L., AND hayman, B. I. 1953. The analysis of diallel crosses. Maize Genetics, Newesletter, 27, 48-58.

RoWLANDS, D. G. 1958. The nature of the breeding system in the field bean ( $V$. $f a b a$ L.) and its relationship to breeding for yield. Heredity, $12,113^{-1} 26$.

SMiTH, D. C. 1944. Pollination and seed formation in grasses. 7. agr. Res., 68, 79-95.

StebBins, G. L. 1950. Variation and Evolution in Plants. Columbia University Press, New York, pp. 643 .

WHitehouse, R. N. H., THOMPSON, J. B., AND DO VAlle Ribeiro, M. A. M. 1958. Studies on the breeding of self-pollinating cereals. 2. The use of a diallel cross analysis in yield production. Euphytica, 7, 147-169. 